\title{
AMENDOIM NHAMBIQUARA
}

\section{Neme Abdo Neme}

O amendoim cultivado pelos índios de Mato Grosso, foi estudado e classificado pelo Dr. F. C. Hoehne, como Arachir nambyquarae Hoehne. Da descrição feita pelo referido autor (1) damos a seguir alguns trechos, que servem para caraterizar os frutos: "legumes de até $9 \mathrm{~cm}$ de comprimento sôbre $2 \mathrm{~cm}$ de grossura, com o pericarpo grosso e um tanto esponjoso, crassamente reticulado em linhas paralelas que estão ligadas por outras transversais : grãos em regra apenas dois em cada legume, (também podem aparecer mais), com a película metade alva e metade verme!ha ou completamente alva, totalmente vermelha ou ainda de outras côres em variedades cultivadas pelos brasilíndios de Mato Grosso, de até $35 \mathrm{~mm}$ de comprimento e mais de $1 \mathrm{~mm}$ de espessura".

Trabalhos comparativos realizados no Instituto Agronômico, desde 1929, infelizmente não justificam o interêsse, for essa espécie de amendoim, que se tem notado por parte de lavradores e técnicos nacionais e estrangeiros. Entretanto, queremos crer que possa ser material apreciável para trabalhos de genética. Os ensaios comparativos de variedades efetuados pela antiga Secção de Agronomia do I. A. revelaram os seguintes resultados (2):

Kg DE FRUTOS POR ALQUEIRE :

\begin{tabular}{|c|c|c|c|c|c|c|c|}
\hline AMENDOIM & $29 \cdot 30$ & $30-31$ & $31-32$ & 32.33 & $33-34$ & 34.35 & Média \\
\hline 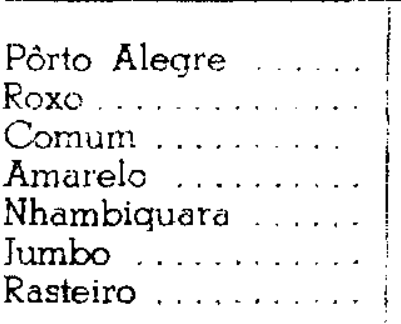 & $\begin{array}{l}4741 \\
6033 \\
4358 \\
5438 \\
5179 \\
5237 \\
4772\end{array}$ & $\begin{array}{l}5937 \\
7976 \\
5870 \\
5265 \\
5601 \\
6273 \\
6049\end{array}$ & $\begin{array}{l}6703 \\
4517 \\
6775 \\
5843 \\
5019 \\
3387 \\
7438\end{array}$ & $\begin{array}{l}5108 \\
6373 \\
3345 \\
4291 \\
3734 \\
5128 \\
4879\end{array}$ & $\begin{array}{l}4600 \\
5108 \\
4093 \\
4615 \\
1679 \\
2808 \\
2046\end{array}$ & $\begin{array}{l}5174 \\
6368 \\
3203 \\
6148 \\
2865 \\
3322 \\
4099\end{array}$ & $\begin{array}{l}53 \% 7 \\
6062 \\
4607 \\
5266 \\
4012 \\
4359 \\
4980\end{array}$ \\
\hline
\end{tabular}

Como se vê pelos dados acima, o amendoim "Nhambiquara" produziu, em média, $2000 \mathrm{~kg}$ menos que o primeiro colocado, amendoim "Roxo". 
Todavia, ainda temos outras questc̃es a considerar, tais como o pêsc de sementes por $\mathrm{kg}$ de frutos e a percentagem de óleo. É certo que as percentagens de óleo variam pouco entre essas variedades de amendoim, com exceção do "Rasteiro", mas, por outro lado, há uma grande diferença na relação pêso de sementes-cascas, conforme se pode avaliar pelos dados abaixo:

\section{AMENDOIM}

Tr: de bleo na substân -ia origina! " "
Pêso de semertes ror lo de frutos (gr)
Fox

Pôtr A Aare

itá

Conzin.

Anision

Watet:

Nhan: 'rlata

Iamb

Patorin

32,02
30.16
$48,1 \%$
50.44
13.60
49.34
50.90
92.24
42.36

32,02

$48: 1$

6) 44

13,61

19 . it:

$32=4$

42,36
700

680

710

730

706

660

310

633

6il?

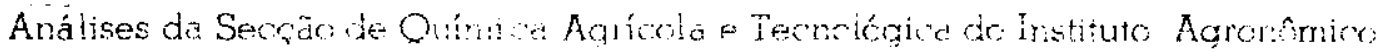

Assim, podemos dizer qut: sob o ponto de vista agrícolo-industrial, o amendoim "Nhambiquara", além de produzir menos por unidade de superfície, tem a desvantagem de produzir muito menor quantidade de sementes por $\mathrm{kg}$ de frutos, menos da metade dos demais.

Há ainda uma particularidade a se mencionar: é a que se refere ao ciclo vegetativo. Os amendoins "Roxo", "Pôrto Alegre", "Comum", "Anarelo", "Tatú" e "Cateto", têm um ciclo que varia de 1.35 .1.40 dias. ao passo que no "Nhambiquara", assim como no "Rasteiro", o ciclo é maior, em média 176 dias.

\section{LITERATURA CITADA}

Hohne, F. C. Flo'd Brasilica 25: 1 20, tas 15. 1940.

$\therefore$ Neme, N. A. a S. C. Sampaio. O Amendon. Pibl. Secr.t. Agr. Ind e Com do Fit. S. Paulo, po. i 31. :9.4?. 